\title{
Rapid Detection and Identification of Dioscorine Compounds in Dioscorea hispida Tuber Plants by LC-ESI-MS
}

\author{
Zatil Hazrati Kamaruddin, ${ }^{\text {a,b }}$ S. M. Sapuan, ${ }^{\text {b* }}$ Mohd Zuhri Mohamed Yusoff, ${ }^{\text {b }}$ and \\ Ridhwan Jumaidin $^{c}$
}

\begin{abstract}
Studies have revealed that Dioscorea hispida tubers contain a poisonous substance called alkaloid dioscorine. The method for removing alkaloid dioscorine in Dioscorea hispida is explored in this research through a soaking process. The tubers were peeled, washed, sliced, and soaked for 5 days in either $1.0 \mathrm{M}$ sodium chloride $(\mathrm{NaCl})$ or distilled water. The aim of this study was to firstly identify the amount of toxic dioscorine remaining after soaking for 5 days, and then determine the best solution for removing dioscorine compounds in the tubers that were obtained from a tropical area in Peninsular Malaysia. The liquid chromatography electrospray ionization mass spectrometric (LC-ESI-MS) systems were used to identify the presence of alkaloid dioscorine compounds within Dioscorea hispida tubers. The analysis showed that no dioscorine compounds were present in day 5 for samples soaked in the $\mathrm{NaCl}$ solution. However, the relative abundance in the distilled water solution at day 5 was 281000 , indicating a $95 \%$ decrease of the relative abundance value of the dioscorine compounds. This work aimed to determine the minimum days needed to remove the poisonous element before Dioscorea hispida tubers could be used for food consumption or for any other applications.
\end{abstract}

Keywords: Dioscorea hispida; Dioscorine compounds; Alkaloid; Foods; LC-ESI-MS

Contact information: a: German Malaysian Institute, Jalan Ilmiah, Taman Universiti, 43000, Kajang, Selangor, Malaysia; $b$ : Advanced Engineering Materials and Composites Research Centre, Department of Mechanical and Manufacturing Engineering, Universiti Putra Malaysia, 43400, Serdang, Selangor, Malaysia; c: Universiti Teknikal Malaysia Melaka, Faculty of Engineering Technology, Mechanical and Manufacturing, Hang Tuah Jaya, 76100 Durian Tunggal, Melaka, Malaysia;

*Corresponding author: sapuan@upm.edu.my

\section{INTRODUCTION}

Dioscorea hispida, locally known as ubi gadong in Malaysia, is a seasonal plant found in tropical regions such as Malaysia, Indonesia, Vietnam, Thailand, and India. The plant can grow up to $20 \mathrm{~m}$ in height and has thorny stems. It is a wild plant with diverse shapes, such as round or oval, and with yellowish-brown skin (Sami and Fata 2019). Recent studies have shown that the Dioscorea species can be eaten after undergoing cooking methods such as baking, frying, and boiling (Kumoro et al. 2019). This plant belongs to the Dioscoreaceae family and is not frequently consumed by the public because it is a toxic species. It contains the dioscorine alkaloid compound, which can be harmful to health (Napisah and Rosma 2020).

The main challenge faced by researchers is the problem of detoxification. Mlingi et al. (1995) state that the safest amount of tubers that can be consumed should not exceed $10 \mathrm{mg}$ of hydrogen cyanide $(\mathrm{HCN})$ per $\mathrm{kg}$ of body weight. Dioscorine can be extremely 
harmful to humans and may result in poisoning with symptoms ranging from vomiting, nausea, stomach pains, and health complications (Gunawan et al. 2019). Dioscorine is a water-soluble alkaloid compound within Dioscorea hispida and has the molecular formula of $\mathrm{C}_{13} \mathrm{H}_{19} \mathrm{O}_{2} \mathrm{~N}$, which is exceptionally toxic. It is well established regarding the tuber's toxicity in the environment and is generally consumed after undergoing a toxic removal process of the dioscorine compound (Irmayadani et al. 2019).

In recent times, there has been growing attention in the agricultural sector for developing biodegradable plastics using Dioscorea hispida tubers, sugar palm (Ilyas et al. 2018, 2019a, 2019b), sago (Halimatul et al. 2019a, 2019b), bengkuang (Syafri et al. 2019), potato (Jumaidin et al. 2019a), cassava (Jumaidin et al. 2019b, 2020), and corn starch (Edhirej et al. 2017). The main form of carbohydrates in natural tubers is starch, which has a high percentage of energy contribution to the human diet (Sanyang et al. 2018; Ilyas and Sapuan 2020; Nazrin et al. 2020). However, plastics developed from Dioscorea hispida starch have definite drawbacks in their structural stability compared to conventional plastics, which are known for their stiffness (Navia and Villada 2005). The Dioscorea hispida tubers are natural fibers with an abundant source of starch and contain lignin, cellulose, hemicellulose, and fibers (Hamid et al. 2019). There are currently only a few published studies focusing on the toxicity removal in Dioscorea hispida tubers and their applications. However, there is no information on the specific duration for removing dioscorine from Dioscorea hispida tubers through a soaking method with sodium chloride or distilled water. It has been reported that sodium chloride solution for soaking process caused differences in osmosis pressure outside and inside the material. The osmosis diffusion occurred from the inner parts of soaked Dioscorea hispida tubers due to the different osmosis pressure after the material being soaked in the sodium chloride solution (Kresnadipayana and Waty 2019).

Liquid chromatography-mass spectrometry is commonly used in many research fields such as in food and safety, environmental, pharmaceuticals, and industrial material purposes (Lee et al. 2019). Studies explain liquid chromatography as the separation of compound elements of a sample according to their retention strength for immobile or mobile phases by identifying the separated elements using electrical conductivity followed by LC-MS specifications (Su et al. 2019). Recent research has been largely exploratory in nature for the detection of primary substances as references, using time retention and peak intensity (Barbieri and Heard 2019). An early example of chromatography research includes determining the best resolution of qualifying and quantifying substances. However, the chromatography process can be tough for simultaneous multiple analyses (Vinale et al. 2020). Twenty cohort study analyses examined the relationship between mass spectrometry (MS), which uses strongly sensitive identification techniques, and the ionization of sample components using multiple methods (Jalal et al. 2018). It was found that the separation of resulting ions in a vacuum was according to the mass charge ratios as well as the intensity of each ion (Brown and Carmical 2019).

The role of the mass spectra provided by MS is to specify the concentration position of ions and has shown that mass is the precise information for certain molecules, together with the ability of MS to obtain direct information for identifying a single component. However, it is different for multiple components to analyze the spectra (Naz et al. 2019). Although some previous research has been carried out on the method to identify dioscorine compounds such as ultraviolet-visible spectrometry (Kresnadipayana and Waty 2019), TLC densitometry, and TLC image analysis (Sasiwatpaisit et al. 2014), no studies have been found which used LC-MS technique. Hence, the combination of LC-MS systems can 
be used to identify the alkaloid dioscorine compounds in Dioscorea hispida tubers (Hajšlová et al. 2018). This is important for determining the amount of dioscorine compounds in Dioscorea hispida tubers that can be used for food consumption or any other applications (Leete and Michelson 1988). To date, little reliable evidence is present on the types of solutions that can be used for removing dioscorine in Dioscorea hispida. This study aimed to determine the dioscorine toxic compound present in Dioscorea hispida tubers after 5 days of soaking through an LC-MS analysis. The Dioscorea hispida tubers were obtained from tropical areas in Peninsular Malaysia and their potential use in the development of biocomposites was investigated.

\section{EXPERIMENTAL}

\section{Materials}

Dioscorea hispida was obtained from fresh tubers from Kuala Terengganu, Malaysia. For the experiment, these tubers went through a process for removing the poisonous element, alkaloid dioscorine. The Dioscorea hispida tubers were extracted following the method employed by Mohd. Hori et al. (2016). Two different types of solutions were prepared: $1.0 \mathrm{M}$ sodium chloride $(\mathrm{NaCl})$ and distilled water. The tuber pieces were soaked for 5 days in each solution. The $\mathrm{NaCl}$ was supplied by Evergreen Engineering and Resources in Sdn Bhd., Malaysia and was used as the solution for removing the toxic elements in Dioscorea hispida.

\section{Sample Preparation}

The Dioscorea hispida (Fig. 1a,b) was cleaned (Fig. 1c) and cut into pieces using a slicer blade having $3 \mathrm{~mm}$ thickness, as shown in Fig. 1d. The pieces were weighed using a digital weighing scale into $25 \mathrm{~g}$ portions, and 5 samples were prepared for the $1.0 \mathrm{M} \mathrm{NaCl}$ and distilled water solutions. The samples were then soaked for 5 days in $500 \mathrm{~mL}$ of the selected solutions (Fig. 1e). After the soaking process, the samples of Dioscorea hispida tubers went through a blending process (Philips NL 9206AD) to produce a solution mixture as preparation for LC-MS (Agilent 6520 Accurate-Mass Q-TOF) alkaloid dioscorine detection.

\section{Liquid Chromatography}

Liquid chromatography-mass spectrometry (LC-MS) was applied to identify the alkaloid dioscorine compound in the solution mixture of Dioscorea hispida tubers after soaking completion based on days 1, 2, 3, 4, and 5. An Agilent 1290 Infinity LC system Santa Clara, CA, USA) coupled with an Agilent 6520 Accurate-Mass Q-TOF mass spectrometer with dual ESI source was used, and the concentration samples were spun at $15000 \mathrm{rpm}$ for $15 \mathrm{~min}$.

The chromatography process was a compound separation method in which two or more elements were separated and optionally spread between two unmixable stages. Liquid chromatography (LC) was performed on an Agilent Zorbax Eclipse XDB-C18 column (narrow-bore $2.1 \times 150 \mathrm{~mm}, 3.5$-micron particle size) at $25^{\circ} \mathrm{C}$. The combination of ultrapurified water $\left(\mathrm{H}_{2} \mathrm{O}\right)$ and acetonitrile $\left(\mathrm{CH}_{3} \mathrm{CN}\right)$ was employed as the mobile phase. The chromatography was conducted using an isocratic mixture and a linear gradient of ACN, which were $5 \%$ at 0 to $5 \mathrm{~min}, 5$ to $100 \%$ at 5 to $20 \mathrm{~min}$, and 5 to $100 \%$ at 20 to $25 \mathrm{~min}$. The column was flushed with acetonitrile at the end of the chromatographic process and re- 
equilibrated for $5 \mathrm{~min}$ between individual runs. The flow rate was $0.5 \mathrm{~mL} / \mathrm{min}$ and the injection volume was $1.0 \mu \mathrm{L}$.
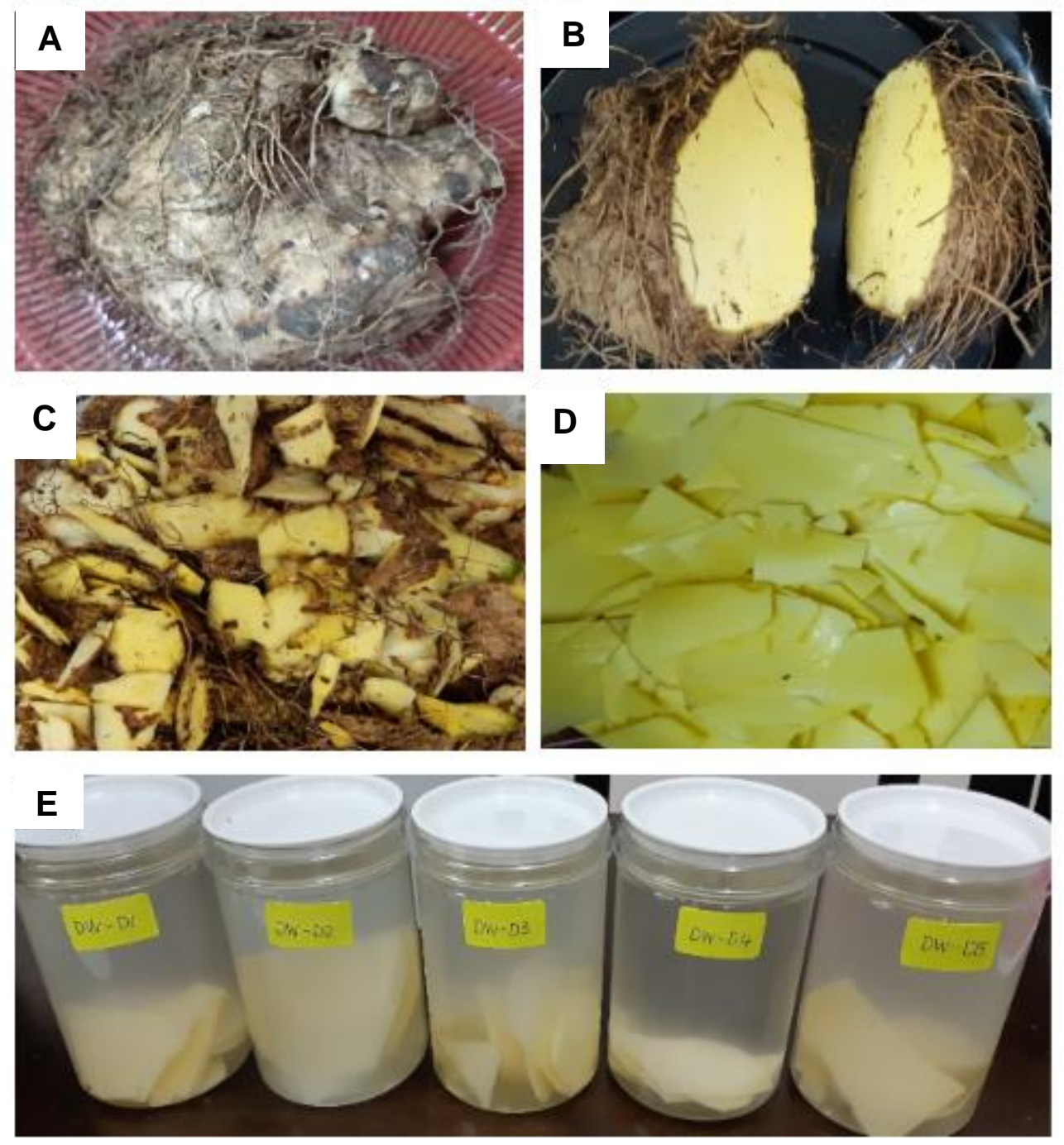

Fig. 1. (A) Irregular-shaped tubers, (B) yellowish-brown Dioscorea hispida, (C) peels of Dioscorea hispida tubers, (D) slices of Dioscorea hispida tubers, (E) soaking process of tubers in $1.0 \mathrm{M}$ $\mathrm{NaCl}$ and distilled water solutions

\section{Mass Spectrometry}

The positive and negative ion LC-MS spectra were obtained on an ion trap Agilent MassHunter Qualitative Analysis B.07.00 using electrospray ionization (ESI). The analysis identified the polarity after optimizing the instrument settings on the ion charge condition and scanning speed. Nitrogen was applied as a drying gas with a flow rate of $10 \mathrm{~L} / \mathrm{min}$, as well as a nebulizer gas at a pressure of $412 \mathrm{kPa}$. The nebulizer temperature was fixed at $300{ }^{\circ} \mathrm{C}$. The mass spectrometer was recorded in the range between 100 to $3200 \mathrm{~m} / \mathrm{z}$, the fragmentor voltage was set at $125 \mathrm{~V}$, and the skimmer voltage was at $65 \mathrm{~V}$.

\section{Compound Identification}

In the compound database structure, the MS data of the original compounds were kept in a library as storage data to be used in the Agilent software. Every sample of the 
specimen was analyzed by MS and the process data were recorded. The fragmentation patterns from the LC-MS results of the unknown compound were cross-checked against those in the library for positive compound identification. Figure 2 presents the compound structure of dioscorine in the Dioscorea hispida tubers.

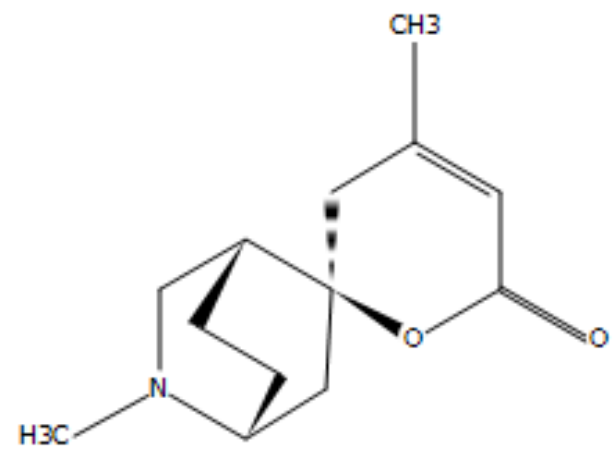

Fig. 2. Dioscorine compound structure (Abiodun et al. 2009)

\section{RESULTS AND DISCUSSION}

\section{Dioscorine Identification by LC-ESI-MS Analysis}

Table 1 provides the experimental data of the Dioscorea hispida soaked in distilled water for 5 days. The results indicate that the dioscorine compound composition clearly showed a decreasing trend of relative abundance values. The dioscorine compound screening used a positive polarity mode from day 1 until day 5 . However, there was a 95\% significant difference between the amount of relative abundance of dioscorine compound for the sample DW-D1 (5373789) to DW-D5 (280835.53). Strong evidence of retention time $\left(R_{t}\right)$ was shown in Table 1, resulting in the positive correlation that the number of days for the soaking process should be increased to remove the toxic elements.

Table 2 provides the experimental data of the soaking process for the Dioscorea hispida samples in the $\mathrm{NaCl}$ solution. A substantial difference can be seen at SC-D1 (375851.63) and SC-D4 (7141.75). However, the sample SC-D5 detected no dioscorine compound on day 5. The result of soaking Dioscorea hispida tubers in the $\mathrm{NaCl}$ solution presented more successful findings compared to the distilled water solution. The $\mathrm{NaCl}$ solution removed the alkaloid dioscorine more rapidly (approximately 98\% amount of relative abundance) compared to distilled water (Kresnadipayana and Waty 2019). The correlation factor is related to different $\mathrm{pH}$ of the solutions. Sodium chloride was more neutral with a $\mathrm{pH} 7$, while distilled water was slightly acidic with a $\mathrm{pH}$ of 5.8 (Hudzari et al. 2012). The abundance amount of dioscorine from these findings specifically supports the hypothesis that the $\mathrm{NaCl}$ solution is a better medium for the soaking process and can efficiently remove the poisonous element in Dioscorea hispida tubers (Biswal and Bozormer 1991).

As shown in Tables 1 and 2, the retention time $\left(R_{\mathrm{t}}\right)$ increased for samples DW-D1 (1.648) to DW-D5 (1.715) in distilled water and SC-D1 (1.693) to SC-D4 (1.718) in the $\mathrm{NaCl}$ solution. These results are consistent with the data obtained from the time measurements taken when the solute passed through the column during the LC-MS analysis. Figure 3 presents a graph comparison regarding the amount of relative abundance in Dioscorea hispida tubers and the different days and solutions used. 


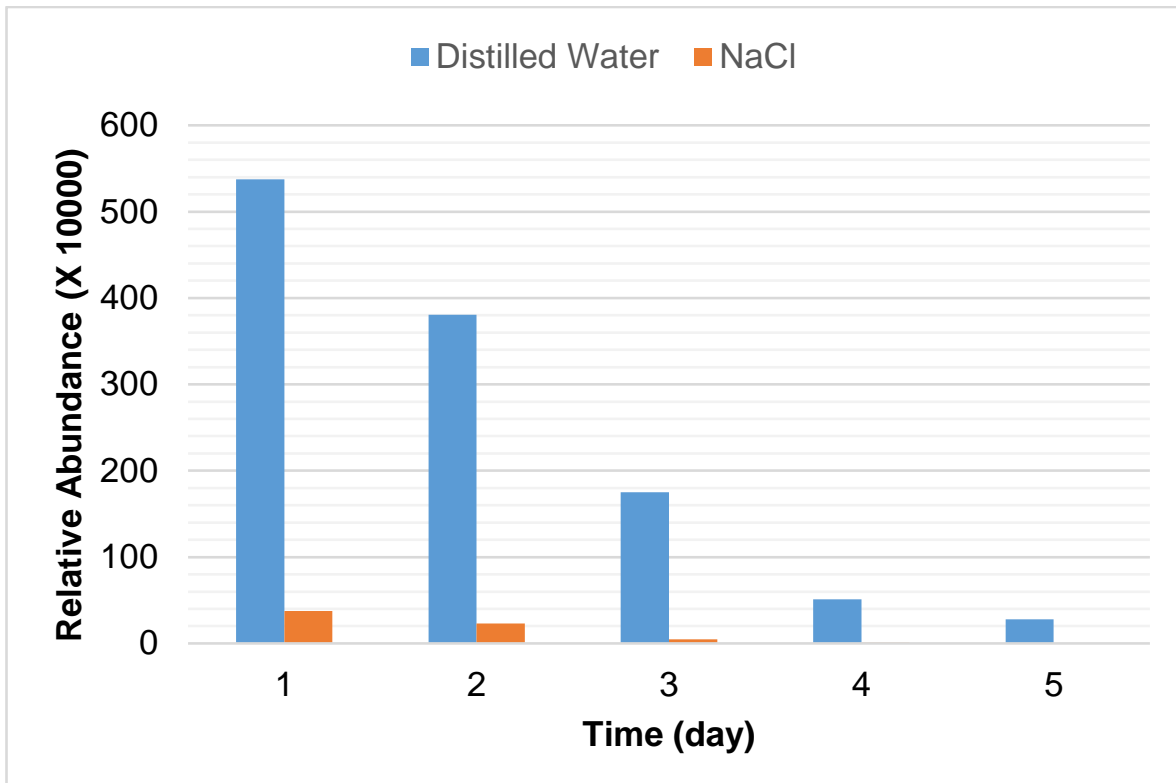

Fig. 3. Relative abundance values in Dioscorea hispida for different days and solutions

Table 1. Distilled Water Samples: Polarity, Relative Abundance, Retention Time at MS Obtained with Dual ESI Sources of Dioscorine Compound

\begin{tabular}{|c|c|c|c|c|}
\hline Samples & Compound & Polarity & Relative Abundance & Retention Time $\left(\mathrm{R}_{\mathrm{t}}\right)$ \\
\hline DW-D1 & Dioscorine & Positive & 5373789 & 1.648 \\
\hline DW-D2 & Dioscorine & Positive & 3806964.25 & 1.661 \\
\hline DW-D3 & Dioscorine & Positive & 1751439.63 & 1.679 \\
\hline DW-D4 & Dioscorine & Positive & 511627.91 & 1.707 \\
\hline DW-D5 & Dioscorine & Positive & 280835.53 & 1.715 \\
\hline
\end{tabular}

Table 2. Sodium Chloride Samples: Polarity, Relative Abundance, Retention Time at MS Obtained with Dual ESI Sources of Dioscorine Compound

\begin{tabular}{|c|c|c|c|c|}
\hline Samples & Compound & Polarity & Relative Abundance & Retention Time $\left(\mathrm{R}_{\mathrm{t}}\right)$ \\
\hline SC-D1 & Dioscorine & Positive & 375851.63 & 1.693 \\
\hline SC-D2 & Dioscorine & Positive & 231581.36 & 1.705 \\
\hline SC-D3 & Dioscorine & Positive & 46796.39 & 1.713 \\
\hline SC-D4 & Dioscorine & Positive & 7141.75 & 1.718 \\
\hline SC-D5 & Dioscorine & Positive & - & - \\
\hline
\end{tabular}

\section{LC-ESI-MS Spectrum and Fragmentation Pathways for Dioscorine}

The LC-MS analysis using ESI is the most popular for identifying the dioscorine compound (Della-Flora et al. 2019). Following the present results, these studies have demonstrated that the dioscorine compound had been protonated to the positive mode. It is possible that the mobile phase of $0.1 \%$ formic acid enhanced the sensitivity and protonation. The soft ionization techniques produced very little fragmentation, which provides evidence on the molecular mass of the compound (Naz et al. 2019). 


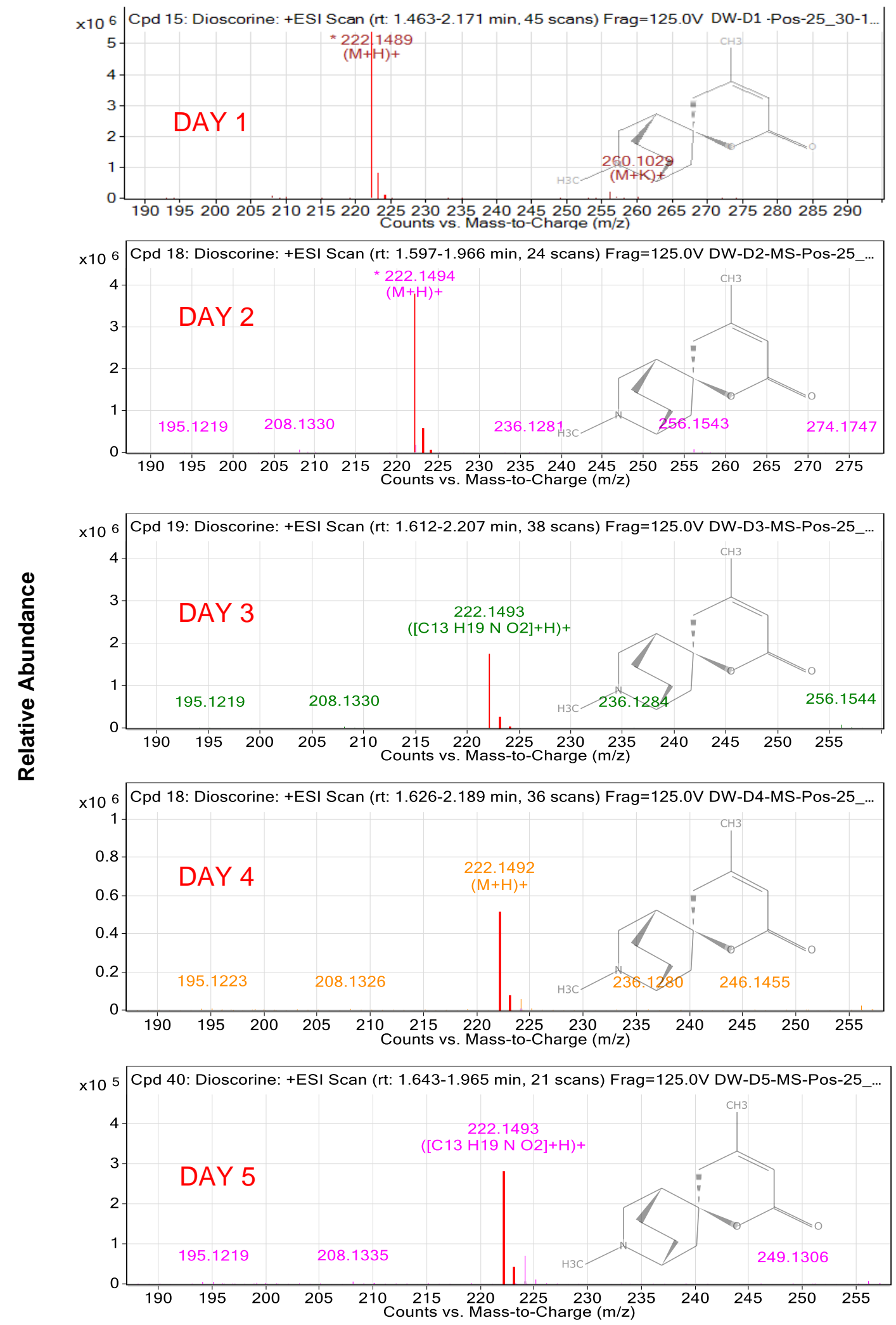

(a)

(b)

(c)

(d)

(e)

Fig. 4. Fragment ion spectra in MS analysis of dioscorine compound for distilled water: (a) DWD1, (b) DW-D2, (c) DW-D3, (d) DW-D4, and (e) DW-D5 
Another possible explanation for the results obtained from the MS analysis (Tables 1 and 2), could be that the liquid-liquid protocols coupled with the LC-ESI-MS based on the selected particle size column for the toxic compounds. The dioscorine compound was identified in the positive ion mode ESI-MS/MS spectra and transferred into the library by using the matches fit score from the dioscorine compound value. The chromatographic separation process in the Dioscorea hispida tuber samples was set by the mass spectrometer to scan the mass range with the upper mass limit. It was identified by the highest molecular weight of the subject compound analysis and the smaller limit by the background of ions. The final scanning process of the samples was stored, and the total ion intensities was produced. The total ion current was stored and computed for the result analysis (Badoud et al. 2010). These are important findings for the retention times of the longest retained component, which were scanned by the mass spectrometer to obtain the data for processing. This is particularly useful for subsequent spectral analyses, which were based on the total ion (TIC) trace obtained from the Dioscorea hispida tuber mixtures. These are due to the appropriate time by retaining the longest retention time and producing the data available for processing. Figure 4 presents the mass spectrometer analysis obtained from the investigation of Dioscorea hispida tubers in the distilled water solution. The first set of analyses examined the identification of the alkaloid dioscorine after 5 days of soaking. The relative abundance amount remarkably decreased from DW-D1 to DW-D5.

Interestingly, the Dioscorea hispida in the $\mathrm{NaCl}$ solution also presented a more rapid decrease of relative abundance from SC-D1 to SC-D4. These results are likely to be related to the osmosis diffusion action when the immersion of Dioscorea hispida tubers using sodium chloride $(\mathrm{NaCl})$ solution is carried out. The osmosis reaction is influenced by the concentration gradient. The higher concentration gradient of sodium chloride, the faster the osmosis reaction will occur (Kresnadipayana and Waty 2019). Table 2 shows that the dioscorine alkaloid content was not detected in sample SC-D5, indicating that the Dioscorea hispida tubers are safe for consumption or to be used for other purposes. The $\mathrm{m} / \mathrm{z}$ ratios coverage of the mass spectrum was produced, whereby the single mass spectrum was provided with complete analytical information for each Dioscorea hispida tuber sample (Müller et al. 2000). These results are consistent with the research and suggest that the use of the sodium chloride solution is quicker in removing the alkaloid in Dioscorea hispida tubers compared to distilled water solution, as shown in Fig. 5 (Oellig and Schmid 2019), which is crucial because the compound may cause food poisoning depending on the toxicity content of the tuber.

The availability of toxic dioscorine was a concern, but the usage of sodium chloride made it easier and faster to remove. This method can effectively minimize the time of preparing Dioscorea hispida compared to soaking in a flowing river water for 7 days, which was demonstrated as a technique for removing the dioscorine compound (Roslan $e t$ al. 2012). Recent studies have been accomplished regarding the application of pesticides, which can benefit from the soaked water technique for Dioscorea hispida. The advancements of food products from Dioscorea hispida will produce a safer outcome for human consumption (Hudzari et al. 2012). 


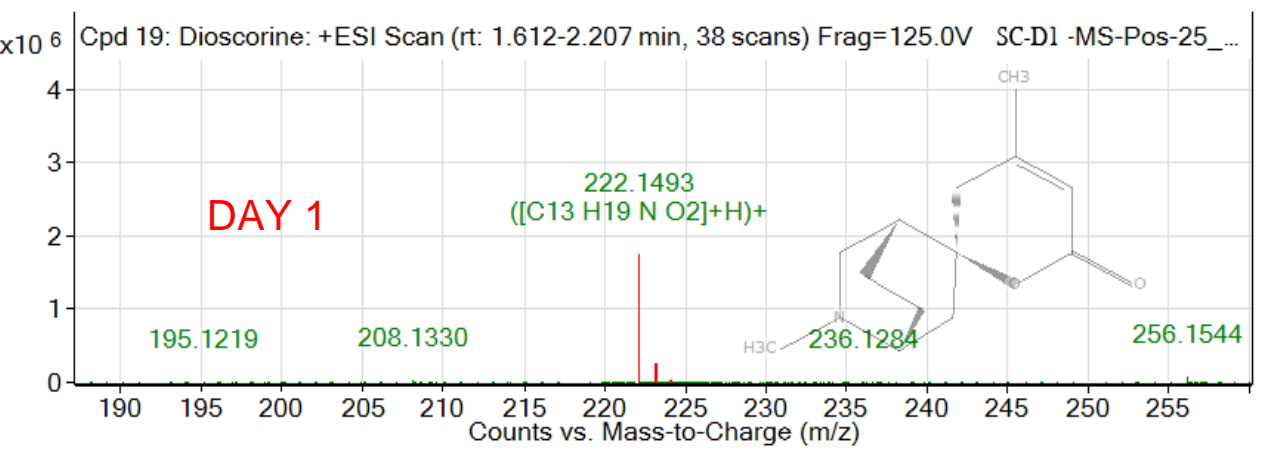

(a)

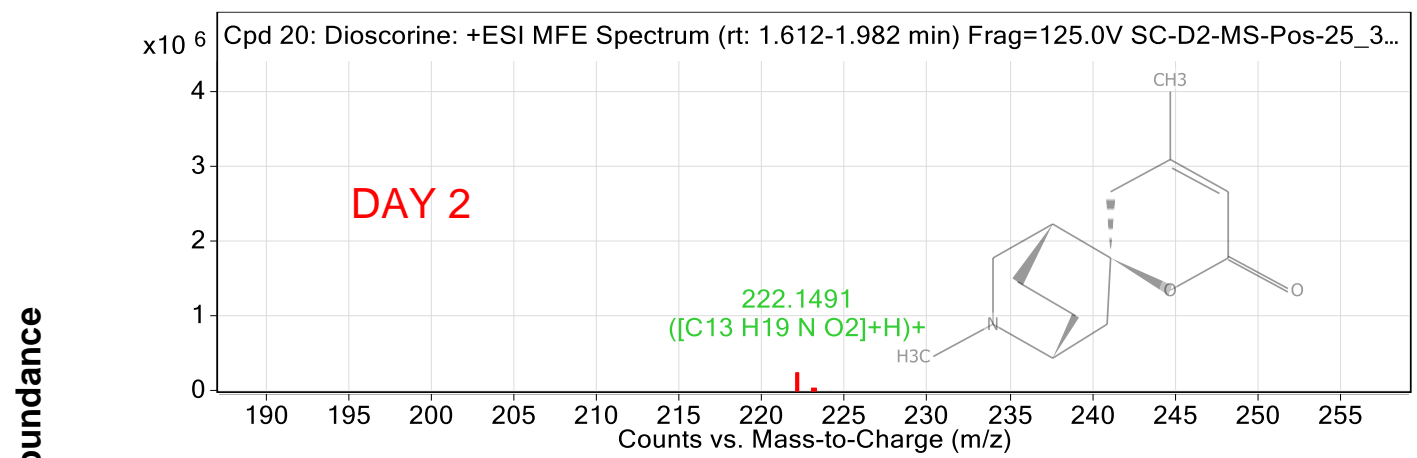

(b)

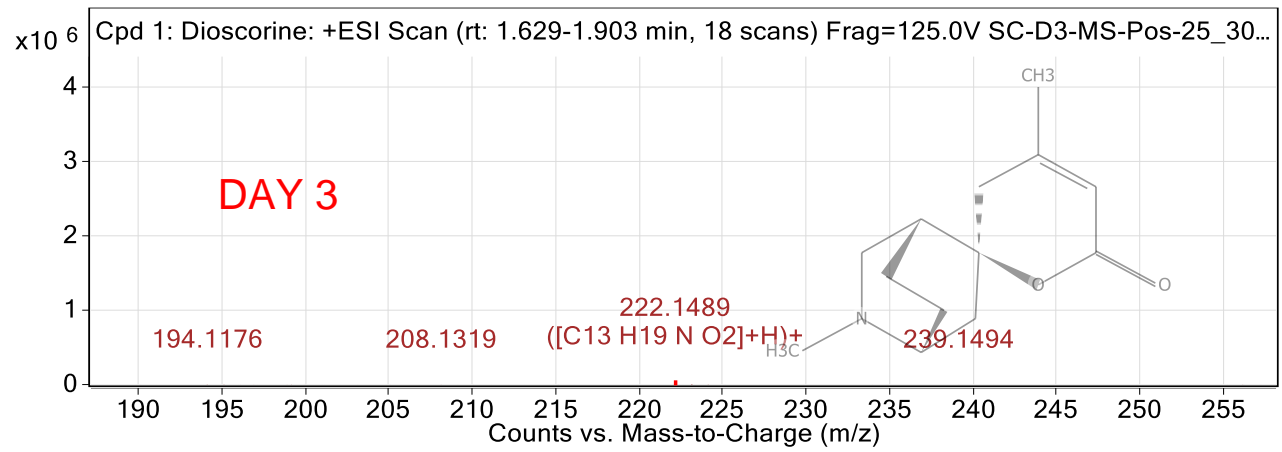

(c)

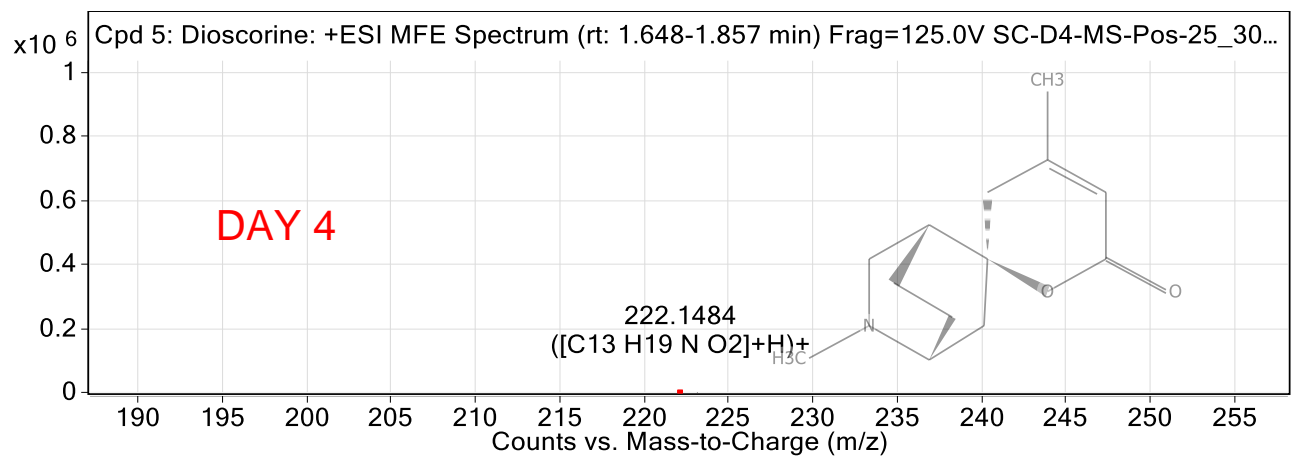

(d)

Fig. 5. Spectra of fragment ions in MS analysis of dioscorine compound for $\mathrm{NaCl}$ : (a) SC-D1, (b) SC-D2, (c) SC-D3, (d) SC-D4 


\section{CONCLUSIONS}

1. The present study was designed to determine the minimum days for removing alkaloid dioscorine in Dioscorea hispida tubers. It was found that the dioscorine compound was removed faster by using the sodium chloride $1.0 \mathrm{M} \mathrm{NaCl}$ solution compared to distilled water.

2. The results from the LC-ESI-MS analysis showed that on day 5, there was no dioscorine detected for soaking in $1.0 \mathrm{M} \mathrm{NaCl}$ compared to 281000 of relative abundance amount in the distilled water solution.

3. This study established a qualitative LC-MS framework for detecting the dioscorine compound, and this approach has proven useful in expanding the understanding of toxic removal in Dioscorea hispida tubers.

\section{ACKNOWLEDGMENTS}

The authors would like to thank the Universiti Putra Malaysia for the financial support provided through the Universiti Putra Malaysia Research Grant Scheme HiCOE (vote number 6369107), as well as the German Malaysian Institute for providing the award to the principal author in this project.

\section{REFERENCES CITED}

Abiodun, O. A., Adegbite, J. A., and Oladipo, T. S. (2009). "Effect of soaking time on the pasting properties of two cultivars of trifoliate yam (Dioscorea dumetorum) flours," Pakistan J. Nutr. 8(10), 1537-1539. DOI: 10.3923/pjn.2009.1537.1539

Badoud, F., Grata, E., Perrenoud, L., Saugy, M., Rudaz, S., and Veuthey, J. L. (2010). "Fast analysis of doping agents in urine by ultra-high-pressure liquid chromatography-quadrupole time-of-flight mass spectrometry. II: Confirmatory analysis," J. Chromatogr. A 1217(25), 4109-4119. DOI: 10.1016/j.chroma.2009.11.001

Barbieri, M., and Heard, C. M. (2019). "Isolation of punicalagin from Punica granatum rind extract using mass-directed semi-preparative ESI-AP single quadrupole LCMS," J. Pharmaceut. Biomed. 166, 90-94. DOI: 10.1016/j.jpba.2018.12.033

Biswal, R. N., and Bozormer, K. (1991). "Equilibrium data for osmotic concentration of potato in nacl water solution," J. Food Process Eng. 14(4), 237-245. DOI: 10.1111/j.1745-4530.1991.tb00134.x

Brown, S., and Carmical, J. (2019). "Phospholipid depletion techniques in LC - MS bioanalysis," in: Sample Preparation in LC-MS Bioanalysis, W. Li, W. Jan, and Y, Fu (eds.), John Wiley \& Sons, Inc., Hokoben, NJ. pp. 52-67. DOI: 10.1002/9781119274315.ch4

Della-Flora, A., Becker, R. W., Benassi, S. F., Toci, A. T., Cordeiro, G. A., Ibáñez, M., Portolés, T., Hernández, F., Boroski, M., and Sirtori, C. (2019). "Comprehensive investigation of pesticides in Brazilian surface water by high resolution mass spectrometry screening and gas chromatography - mass spectrometry quantitative 
analysis," Sci. Total Environ. 669, 248-257. DOI: 10.1016/j.scitotenv.2019.02.354

Edhirej, A., Sapuan, S. M., Jawaid, M., and Zahari, N. I. (2017). "Preparation and characterization of cassava bagasse reinforced thermoplastic cassava starch," Fiber Polym. 8, 162-171. DOI: 10.1007/s12221-017-6251-7

Gunawan, S., Aparamarta, H. W., Anindita, B. P., and Antari, A. T. (2019). "Effect of fermentation time on the quality of modified gadung flour from gadung tuber (Dioscorea hispida Dennst.)," in: Broad Exposure to Science and Technology 2019, Bali, Indonesia. DOI: 10.1088/1757-899X/673/1/012002

Hajšlová, J., Schulzová, V., Botek, P., and Lojza, J. (2018). "Natural toxins in food crops and their changes during processing," Czech J. Food Sci. 22, S29-S34. DOI: 10.17221/10606-cjfs

Halimatul, M. J., Sapuan, S. M., Jawaid, M., Ishak, M. R., and Ilyas, R. A. (2019a). "Effect of sago starch and plasticizer content on the properties of thermoplastic films: Mechanical testing and cyclic soaking-drying," Polimery. 64(6), 32-41. DOI: 10.14314/polimery.2019.6.5

Halimatul, M. J., Sapuan, S. M., Jawaid, M., Ishak, M. R., and Ilyas, R. A. (2019b). "Water absorption and water solubility properties of sago starch biopolymer composite films filled with sugar palm particles," Polimery. 64(9), 27-35. DOI:10.14314/polimery.2019.9.4

Hamid, Z. A. A., Idris, M. H. M., Arzami, N. A. A. B., and Ramle, S. F. M. (2019). "Investigation on the chemical composition of Discorea hispida dennst (Ubi Gadong)," AIP Conf. Proc. 2068. DOI: 10.1063/1.5089340

Hudzari, R. M., Ssomad, M. A. H. A., Rizuwan, Y. M., Asimi, M. N. N., and Abdullah, A. B. C. (2012). "Development of automatic alkaloid removal system for Dioscorea hispida," Front. Sci. 1(1), 16-20. DOI: 10.5923/j.fs.20110101.03

Ilyas, R. A., and Sapuan, S. M. (2020). "The preparation methods and processing of natural fibre bio-polymer composites," Current Organic Synthesis. 16(8), 1068-1070. DOI:10.2174/157017941608200120105616

Ilyas, R. A., Sapuan, S. M., Atiqah, A., Ibrahim, R., Abral, H., Ishak, M. R., Zainudin, E. S., Nurazzi, N. M., Atikah, M. S. N., Ansari, M. N. M., Asyraf, M. R. M., Supian, A. B. M., \& Ya, H. (2019a). "Sugar palm ( Arenga pinnata [Wurmb .] Merr ) starch films containing sugar palm nanofibrillated cellulose as reinforcement: Water barrier properties," Polymer Composites. 41(2), 459-467. DOI: 10.1002/pc. 25379

Ilyas, R. A., Sapuan, S. M., Ibrahim, R., Abral, H., Ishak, M. R., Zainudin, E. S., Atikah, M. S. N., Mohd Nurazzi, N., Atiqah, A., Ansari, M. N. M., Syafri, E., Asrofi, M., Sari, N. H., and Jumaidin, R. (2019b). "Effect of sugar palm nanofibrillated cellulose concentrations on morphological, mechanical and physical properties of biodegradable films based on agro-waste sugar palm (Arenga pinnata (Wurmb.) Merr) starch," Journal of Materials Research and Technology, 8(5), 4819-4830. DOI: 10.1016/j.jmrt.2019.08.028

Ilyas, R. A., Sapuan, S. M., Ishak, M. R., and Zainudin, E. S. (2018). "Development and characterization of sugar palm nanocrystalline cellulose reinforced sugar palm starch bionanocomposites," Carbohydrate Polymers. 202, 186-202. DOI: 10.1016/j.carbpol.2018.09.002

Irmayadani, T. M. I., Yopi, and Febriani. (2019). "Preliminary study of bioethanol production by Saccharomyces cerevisiae BTCC12 utilizing hydrolysis products of Dioscorea hispida tubers," in: The $3^{\text {rd }}$ International Conference on Natural and Enviornmental Sciences, Banda Aceh, Indonesia. DOI: 10.1088/1755- 


\section{5/364/1/012004}

Jalal, R. S., Weber, J. F. F., and Manshoor, N. (2018). "Dereplication of oligostilbenes in dipterocarpaceous plants using LCMS-ESI-Ion trap-database," J. Liq. Chromatogr. R. T. 41(4), 161-169. DOI: 10.1080/10826076.2018.1428200

Jumaidin, R., Ilyas, R. A., Saiful, M., Hussin, F., and Mastura, M. T. (2019a). "Water transport and physical properties of sugarcane bagasse fibre reinforced thermoplastic potato starch biocomposite," Journal of Advanced Research in Fluid Mechanics and Thermal Sciences. 61(2), 273-281.

Jumaidin, R., Khiruddin, M. A. A., Asyul Sutan Saidi, Z., Salit, M. S., and Ilyas, R. A. (2020). "Effect of cogon grass fibre on the thermal, mechanical and biodegradation properties of thermoplastic cassava starch biocomposite," International Journal of Biological Macromolecules. 146, 746-755. DOI: 10.1016/j.ijbiomac.2019.11.011

Jumaidin, R., Saidi, Z. A. S., Ilyas, R. A., Ahmad, M. N., Wahid, M. K., Yaakob, M. Y., Maidin, N. A., Rahman, M. H. A., and Osman, M. H. (2019b). "Characteristics of cogon grass fibre reinforced thermoplastic cassava starch biocomposite: Water absorption and physical properties," Journal of Advanced Research in Fluid Mechanics and Thermal Sciences 62(1), 43-52.

Kumoro, A. C., Retnowati, D. S., Ratnawati, R., and Widiyanti, M. (2019). "Effect of temperature and reaction time on the swelling power and solubility of gadung (Dioscorea hispida dennst) tuber starch during heat moisture treatment process," $J$. Phys. Conf. Ser. 1295. DOI: 10.1088/1742-6596/1295/1/012062

Kresnadipayana, D., and Waty, H. (2019) "The concentration of $\mathrm{NaCl}$ soaking to decreasing cyanide levels in Gadung (Dioscorea hispida Dennst)," Jurnal Teknologi Laboratorium. 8(1), 36-40 DOI: 10.29238/teknolabjournal.v8i1.156

Lee, B. I., Park, M., Shin, S., Byeon, J., Park, Y., Kim, N., Choi, J., and Shin, Y. G. (2019). "Quantitative analysis of tozadenant using liquid plasma and its human pharmacokinetics prediction pharmacokinetic modeling," Molecules 24(7), 1295. DOI: $10.3390 /$ molecules24071295

Leete, E., and Michelson, R. H. (1988). "Biosynthesis of dioscorine from trigonelline," Phytochemistry 27(12), 3793-3798. DOI: 10.1016/0031-9422(88)83019-X

Mlingi, N. L. V., Bainbridge, Z. A., Poulter, N. H., and Rosling, H. (1995). “Critical stages in cyanogen removal during cassava processing in southern Tanzania," Food Chem. 53(1), 29-33. DOI: 10.1016/0308-8146(95)95782-2

Mohd Hori, N. A. F., Mohd Nasir, N. F., Mohd, N. A., Cheng, E. M., and Sohaimi, S. N. (2016). "The fabrication and characterization of hydroxyapatite-ubi gadong starch based tissue engineering scaffolds," in: 2016 - IEEE-EMBS Conf. Biomed. Eng. Sci., Kuala Lumpur, Malaysia, pp. 220-225. DOI: 10.1109/IECBES.2016.7843446

Müller, C., Vogt, S., Goerke, R., Kordon, A., and Weinmann, W. (2000). "Identification of selected psychopharmaceuticals and their metabolites in hair by LC/ESI-CID/MS and LC/MS/MS," Forensic Sci. Int. 113(1-3), 415-421. DOI: 10.1016/S03790738(00)00202-4

Napisah, H., and Rosma, A. (2020). "Fermentation of Dioscorea hispida oligosaccharides as prebiotic potential by lactic acid bacteria and bifidobacterium," in: The Third Bioprocessing and Biomanufacturing Symposium, Perak, Malaysia. DOI: 10.1088/1757-899X/716/1/012005

Navia, D. P., and Villada, H. S. (2005). "Thermoplastic cassava flour," in: Thermoplastics Elastomers, A. El-Sonbati (ed.), Intech Open, London, UK. DOI: $10.5772 / 34217$ 
Naz, A., Iqtadar, R., Ahmed, F., and Ul-haq, Z. (2019). "Degradation kinetics of fluvoxamine in buffer solutions : In silico ADMET profiling and identification of degradation products by LC-MS / ESI," Arab. J. Chem. 13(2), 4134-4146. DOI: 10.1016/j.arabjc.2019.06.001

Nazrin, A., Sapuan, S. M., Zuhri, M. Y. M., Ilyas, R. A., Syafiq, R., and Sherwani, S. F. K. (2020). "Nanocellulose reinforced thermoplastic starch (TPS), polylactic acid (PLA), and polybutylene succinate (PBS) for food packaging applications," Frontiers in Chemistry. 8(213), 1-12. DOI: 10.3389/fchem.2020.00213

Oellig, C., and Schmid, S. (2019). "Polyethyleneimine as weak anionic exchanger adsorbent for clean-up in pesticide residue analysis of fruits and vegetables," $J$. Chromatogr. A 1597, 9-17. DOI: 10.1016/j.chroma.2019.03.020

Roslan, S., Razali, M. H. H., and Ismail, W. I. W. (2012). "An overview for the application of multispectral device for determination of alkaloid level in Dioscorea hispida," Sci. J. Rev. 1(3), 53-57.

Sami, M., and Fata, K. (2019). "Application of janeng fruit (Dioscorea hispida dennst) on mortality killing the golden," in: International Conference on Science and Innovated Engineering (I-COSNE), Aceh, Indonesia. DOI: 10.1088/1757-899X/536/1/012153

Sanyang, M. L., Ilyas, R. A., Sapuan, S. M., and Jumaidin, R. (2018). "Sugar palm starch-based composites for packaging applications," in: Bionanocomposities for Packaging Applications, M. Jawaid, S. K. Swain (eds.), Springer International Publishing, New York, NY. pp. 125-147.

Sasiwatpaisit, N., Thitikornpong, W., Palanuvej, C., and Ruangrungsi, N. (2014). "Dioscorine content in Dioscorea hispida dried tubers in Thailand by TLCdensitometry and TLC image analysis," J. Chem. Pharm. Res. 6(4), 803-806.

Su, H., Liu, K. T., Chen, B. H., Lin, Y. P., Jiang, Y. M., Tsai, Y. H., Chang, F. R., Shiea, J., and Lee, C. W. (2019). "Rapid identification of herbal toxins using electrospray laser desorption ionization mass spectrometry for emergency care," J. Food Drug Anal. 27(2), 415-427. DOI: 10.1016/j.jfda.2018.11.001

Syafri, E., Sudirman, Mashadi, Yulianti, E., Deswita, Asrofi, M., Abral, H., Sapuan, S. M., Ilyas, R. A., and Fudholi, A. (2019). "Effect of sonication time on the thermal stability, moisture absorption, and biodegradation of water hyacinth (Eichhornia crassipes) nanocellulose-filled bengkuang (Pachyrhizus erosus) starch biocomposites," Journal of Materials Research and Technology 8(6), 6223-6231. DOI: 10.1016/j.jmrt.2019.10.016

Vinale, F., Salvatore, M. M., Nicoletti, R., Staropoli, A., Manganiello, G., Venneri, T., Borrelli, F., Dellagreca, M., Salvatore, F., and Andolfi, A. (2020). "Identification of the main metabolites of a marine-derived strain of Penicillium brevicompactum using LC and GC MS techniques," Metabolites 10(2), 55. DOI: 10.3390/metabo10020055

Article submitted: April 5, 2020; Peer review completed: May 31, 2020; Revised version received: June 5, 2020; Accepted: June 10, 2020; Published: June 17, 2020.

DOI: 10.15376/biores. 15.3.5999-6011 